\title{
PATHOLOGIC CHANGES IN MUSCLE AS A RESULT OF DISTURBANCES OF CIRCULATION
}

\author{
AN EXPERIMENTAL STUDY OF VOLKMANN'S ISCHEMIC PARALYSIS * \\ BARNEY BROOKS, M.D. \\ ST. LOUIS
}

Stenson ${ }^{1}$ first called attention to the fact that paralysis of the posterior extremities of an animal may follow occlusion of the abdominal aorta. Schiffer ${ }^{2}$ believed this paralysis was of central, rather than peripheral, origin. Volkmann ${ }^{3}$ described a paralysis and contracture of muscles which followed the application of a constricting bandage and expressed the opinion that the cause of this condition was obstruction of the arteries and anemia of the muscles of the constricted extremity. Leser ${ }^{4}$ reported seven instances in which paralysis and contracture of muscles followed the application of constricting bandages, and from animal experiments he believed that the paralysis and contracture of the muscles was caused by a deprivation of the muscles of arterial blood. Both Volkmann and Leser recognized that the paralysis and contracture were associated with marked manifestations of inflammation.

Since Volkmann's paper it has become customary to refer to all cases of muscle paralyses and contractures following constrictions of extremities as Volkmann's ischemic paralysis or Volkmann's ischemic contracture. The number of cases recorded in the literature is not large. Powers ${ }^{5}$ was able to collect only fifty-two instances. The frequency of this condition is certainly much greater than one would be led to believe from the number of reported instances. Leser ${ }^{4}$ describes the clinical manifestation of Volkmann's ischemic paralysis as follows:

Shortly after the constricting bandage is applied to the forearm, the hand begins to swell and there is severe pain. The patient may complain of numbness or parasthesia of the fingers. The pain and swelling may develop so rapidly that the bandage is removed in an hour. If the bandage is removed only after

* From the Department of Surgery, Washington University Medical School.

1. Stenson: Elementorum Myologiae Specimen, Florence, 1667; quoted by Hailer: Elementa Physiol. 4:544.

2. Schiffer: Centralbl. f. d. med. Wissensch. 6:579, 1869.

3. Volkmann, Pitha and Billroth: Handbuch der Chirurgie 2:846, 1882.

4. Leser, E.: Saml. klin. Vortr. 3:2087, 1884.

5. Powers, C. A.: The Ischemic Paralysis and Contracture of Volkmann, J. A. M. A. 48:759 (March 2) 1907. 
twenty-four hours. then the fingers show marked contracture and the muscles of the forearm feel hard and stiff. Not the slightest active movement is possible and attempts at passive movement of the fingers cause great pain.

Soon after the removal of the bandage, often within an hour, a marked swelling in the muscles of the forearm begins. This acute inflammatory reaction in the muscles reaches a maximum in about twenty-four hours and then gradually subsides and a marked contracture of the muscles follows.

The pathogenesis of Volkmann's ischemic paralysis was believed by him to be as follows: The paralysis and contracture which follow a constricting bandage applied to the forearm, or which occurs less commonly in the lower extremity, are of ischemic origin. They may be entirely independent of pressure on nerves. They are the result of a deprivation of the extremity of arterial blood. An accompanying venous stasis merely hastens the development of the pathologic condition. The deprivation of the muscle of oxygen results in a degeneration of the muscle fibers and later their absorption. The contracture is to be considered simply as a rigor mortis. It is characteristic of the condition that paralysis and contracture develop simultaneously.

Other views have been recorded as regards the pathogenesis of Volkmann's ischemic paralysis. Bardenheuer ${ }^{6}$ believed that the pathologic condition in the muscles was caused by vascular disturbance in the nature of a venous stasis and that the degeneration of the muscle fibers was due to toxic metabolic products which are retained in the muscle. Rowlands ' believed that the paralysis and contracture are the result of the sudden relief of pressure on the muscle, allowing the blood to congest the muscle. J. B. Murphy ${ }^{8}$ writes:

We believe that it is a pressure ischemic myositis from hemorrhage and effusion into the muscles, aided by the constriction of a splint or bandage or a tight skin, which leads to a myositis from pressure anemia and later to a contracture of the muscle as a whole and, therefore, a shortening of the muscle tendon.

As the result of a fracture, the tissues are bruised; a blood and serum effusion follows, and the tension in the subfascial zone in the forearm can be so great as to cause cyanosis of the whole forearm and hand. A blood clot forms in the tissues and inflammation follows with a deposit of inflammatory products in the tissues. We believe injury to the artery plays little or no rôle in the destruction of the protoplasm of the muscle cells. . . . The obstruction is in the veins and not the arteries. . . The radial pulsations are present throughout the entire course of some of the cases.

Others, as, for example, Thomas, believe the paralysis and coniracture following the application of a constricting bandage to be due

6. Bardenheuer: Deutsch. Ztschr. f. Chir. 108:44, 1911.

7. Rowlands: Lancet 2:1168, 1905.

8. Murphy, J. B.: Myositis, J. A. M. A. 63:1249 (Oct. 10) 1914. 
primarily to nerve injury. Still others comment on the more or less constant association of primary muscle injury and nerve lesions in these cases.

The pathologic condition found in the muscles of patients with Volkmann's ischemic paralysis has been described by Leser and Powers.

Powers described the muscles as they appeared in a patient operated upon sixteen months after the onset of the disease. The muscles were pale red and very tough and fibrous. Microscopic examination revealed a great hyperplasia of connective tissue around and between the bundles of muscle fibers. The connective tissue was dense and consisted chiefly of adult connective tissue fibers containing a moderate number of blood vessels, most of which had well developed walls. This fibrosis was so complete that in many areas no muscle tissue was present. Muscle tissue appeared atrophic and fragmented. Many fibers had lost their nuclei and transverse striations, having the appearance of broad ribbons of delicate fibrillar tissue. Other fibers had a glassy homogeneous appearance, with a marked affinity for acid stains. Their appearance and reaction strongly suggested hyaline degeneration. Osmic acid preparations showed a moderate amount of fatty infiltration of the connective tissue. No fatty degeneration of muscle fibers was found.

Leser described the appearance of muscle tissue removed from a patient suffering with a Volkmann's contracture of six weeks' duration or longer. In gross the muscle was much paler than normal. On microscopic examination the muscle fibers showed evidences of degeneration manifested by breaking up of the fibers into Bowman's disks, loss of muscle nuclei and marked decrease in the size of the muscle fibers. There was no fatty degeneration of the muscle. There were evidences of an acute inflammatory reaction manifested by a marked leukocytic infiltration. There was also a marked growth of very cellular connective tissue, which in many areas had completely replaced muscle tissue. The author describes in detail the endothelium of small vessels. It was not flat but thick. This he interprets as being due to the fact that endothelial cells are elastic, and, hence, when the blood pressure in small vessels was decreased, the endothelium became much thicker. He states that the changes seen in the muscle indicated two processes at work: (1) degeneration of the muscle tissue; (2) a marked inflammatory process in the muscle.

In addition to the paralysis and contractures which follow the application of constricting bandages, paralysis following ligature of large arteries for wounds has been described by Sherril, ${ }^{9}$ Hirschmann, ${ }^{10}$

9. Sherril: Old Dominion J. 18:113, 1914.

10. Hirschmann: Zentralb1. f. Chir. 44:239, 1917. 
Verdeht, ${ }^{11}$ Burrows ${ }^{12}$ and Leriche. ${ }^{13}$ Leriche believed that the paralyses were not due so much to the actual damage to the artery as to the accompanying vasomotor nerves. Desplats and Buquet thought the paralyses were due to temporary or permanent ischemia of the terminals of the nerves. Burrows thought the paralyses and anesthesias following the ligature of large arteries were both of ischemic and reflex nature. In the former there was complete cessation of the pulse in the large arteries, subjective sensations of pins and needles, stocking and glove anesthesia and muscular paralysis with the muscles hard and inelastic. In the reflex paralysis the pulse in the larger arteries was not completely lost. There were no subjective sensations. There was widespread anesthesia and muscular paralyses in which the muscles were soft and flaccid.

In a single case in which extensive paralysis followed ligature of the popliteal artery, the gross and microscopic appearance of the paralyzed muscles, from eleven to fourteen days after the injury, was described. The muscle gave the appearance of an anemic infarct. The muscle fibers and interstitial tissue stained a uniform pink with eosin. The muscles showed extensive degeneration. Some preserved their striae but no nuclei. Others appeared as granular masses. Some were broken transversely into disks and others split longitudinally into fibrillae. The interstitial tissue was edematous and almost no nuclei were seen. There was but a slight trace of inflammatory reaction.

Tinel ${ }^{14}$ writes concerning ischemic paralysis thus:

In the first phase of ischemic paralysis of the upper extremity the affected limb is edematous, cyanosed and cool. After a period of two or three months, there is fibrous transformation of this edema. This progressive sclerosis makes the subcutaneous cellular tissue puffy, invades the dermis, contracts the muscles, hardens the aponeuroses, submerges the tendons and synovial sheaths into a veritable fibrous mass, gives the tissue a woody consistence, and finally transforms the hand into a fibrous bat. With this characteristic appearance are associated certain signs. There is a complete absence or marked diminution in the radial pulse with a much lower blood pressure than on the nonaffected side. There is almost always pain, accompanied by subjective sensation, as burning, tingling or formication. Deep pressure or contact with heat or cold is often very painful. Some cases of ischemic paralysis are almost free from pain. In contrast with this painful sensibility which appears to be deep seated, there is usually considerable anesthesia affecting all the superficial sensations. The anesthesia predominates at the extremity of the limb and decreases toward its origin. The electrical reactions of the muscles are profoundly disturbed. We find the typical reaction of degeneration, particularly hyperexcitability, sometimes with abolition of all electrical excitability. This is rather the syndrome of fibrous

11. Verdeht: J. de méd. d. Bordeaux 87:50, 1916.

12. Burrows, H.: Brit. M. J. 1:199 (Feb. 16) 1918.

13. Leriche: Rev. d. méd. 30:578, 1916.

14. Tinel, J.: Nerve Wounds, New York, William Wood \& Co., 1917. 
transformation of the muscles. The muscles may react only to a very intense current. There is no polar inversion and often stimulation of the nerve at a distance provokes movements more readily than does excitation of the muscle.

It would seem, therefore, from these clinical observations that there was such a thing as a paralysis of muscles following an obstruction of the blood supply to these muscles, and that the paralysis might be independent of injury to nerve trunks. The evidence, however, for such a conclusion is not complete since the possibility of injury to nerve trunks has always to be considered in instances in which wounds of vessels have occurred or instances in which constricting bandages are applied to an extremity. It is worth while noting here that actual paralysis of muscles is not noted in a collection of ligations of great ressels, such as, for example, in that of Halsted's collection of instances of ligation of the common iliac artery, although gangrene of the extremity was noted in a considerable number of instances. Furthermore, paralysis of muscles does not accompany progressive obliteration of arteries in arteriosclerosis even when the occlusion is so extensive as to cause gangrene.

There are two distinct phases of ischemia which have not been differentiated. The arterial blood supply to an extremity may be markedly decreased over an indefinite period or the extremity may be completely deprived of blood for a limited period only. The susceptibility of the various tissues concerned to these different types of ischemia has not been studied.

The results of the obstruction of the veins alone or the arteries alone of an isolated muscle have not been studied.

EXPERIMENTS WITH TOURNIQUETS, SPLINTS, AND PLASTER BANDAGES

Three experiments in which constricting bandages were applied to the extremity were carried out. In one instance a tight muslin bandage was applied above the elbow of a $\operatorname{dog}$ and left in place for twentyfour hours. The animal was given frequent doses of morphin in order to prevent as much as possible the severe pain which would seem almost certainly to accompany such a procedure. At the end of this time, the extremity distal to the bandage was very much swollen and cold. The bandage was removed. The swelling promptly disappeared and no paralysis was observed. In another experiment a very tight Esmarch rubber bandage was applied above the elbow of a dog and left in position for a period of five hours. When it was removed there was complete paralysis of the muscles of the extremity distal to the bandage, and, apparently, a marked impairment of sensation. The animal was allowed to live for a period of three weeks, during which time the paralysis remained complete. The muscles, however, remained soft and flaccid, and microscopic examination revealed nothing more than 
the decrease in size of the fibers and the loss of definition of the striation which is seen after nerve section. In another experiment a tight rubber bandage was applied above a dog's elbow and left in place for five hours. A complete paralysis of the fore leg resulted. The animal was anesthetized on the following day and the nerves and muscles exposed. It was found that stimulation of the nerve trunks above the level of the tourniquet caused no muscle contractions, while stimulation of the same nerves below the level of the tourniquet caused prompt contraction of the muscles.

From these and a few other preliminary experiments, it seemed that with any method of constriction of the entire extremity it was difficult to separate the effect of direct pressure on the nerves and the circulatory disturbance of the various tissues as causes of any paralysis obtained. Furthermore, the degree and character of circulatory disturbance could not be controlled.

\section{EXPERIMENTS IN WHICH THERE WAS PERMANENT OBSTRUCTION OF THE PRIMARY ARTERIES OF AN EXTREMITY}

The circulation in the $\mathrm{dog}$ is of such a nature that ligation of any single, large, peripheral artery produces no disturbance in circulation of sufficient degree to alter the function of an extremity. A marked disturbance in the function of the posterior extremities, however, does follow ligature of the abdominal aorta between the origins of the inferior mesenteric and iliac arteries. The function of one posterior extremity may be altered by unilateral multiple ligations of the terminal branches of the aorta. That this disturbance in function is not due to any disturbance in circulation in the spinal cord is clearly shown by the fact that none of the arteries ligated send any branches to this structure; and, furthermore, the artery may be obstructed for several hours and on removal of the obstruction there may be a complete recovery from the paralysis. This is in contradiction to the known fact that the brain and cord will not recover function after much shorter periods of anemia.

\section{REPORT GF EXPERIMENTS}

EXPfRIMENT 101.-Dog 41, a large female, was operated on under ether anesthesia, May 19,1921. The abdomen was opened; the aorta was ligated proximal to the origin of the iliac arteries and the abdomen was closed. Five hours after operation, the animal was standing in the cage. Both thighs were warm. The legs and feet were "cool" but not "cold." Twenty-four hours after operation the animal was taken from the cage. It walked with the hind legs held rather stiffly; but it started walking with very little difficulty. After walking about 100 feet ( 30.5 meters) the hind legs began to "give way"; and after a few minutes of effort to walk, the hind legs became apparently completely useless. The 
animal was allowed to rest for three hours, after which the experience described ahove was repeated. At this time the disalility appeared after somewhat more exertion.

After three days the animal was apparently quite normal and did not show any eviclence of wakness in the hind legs after lifteen minutes walking. Four

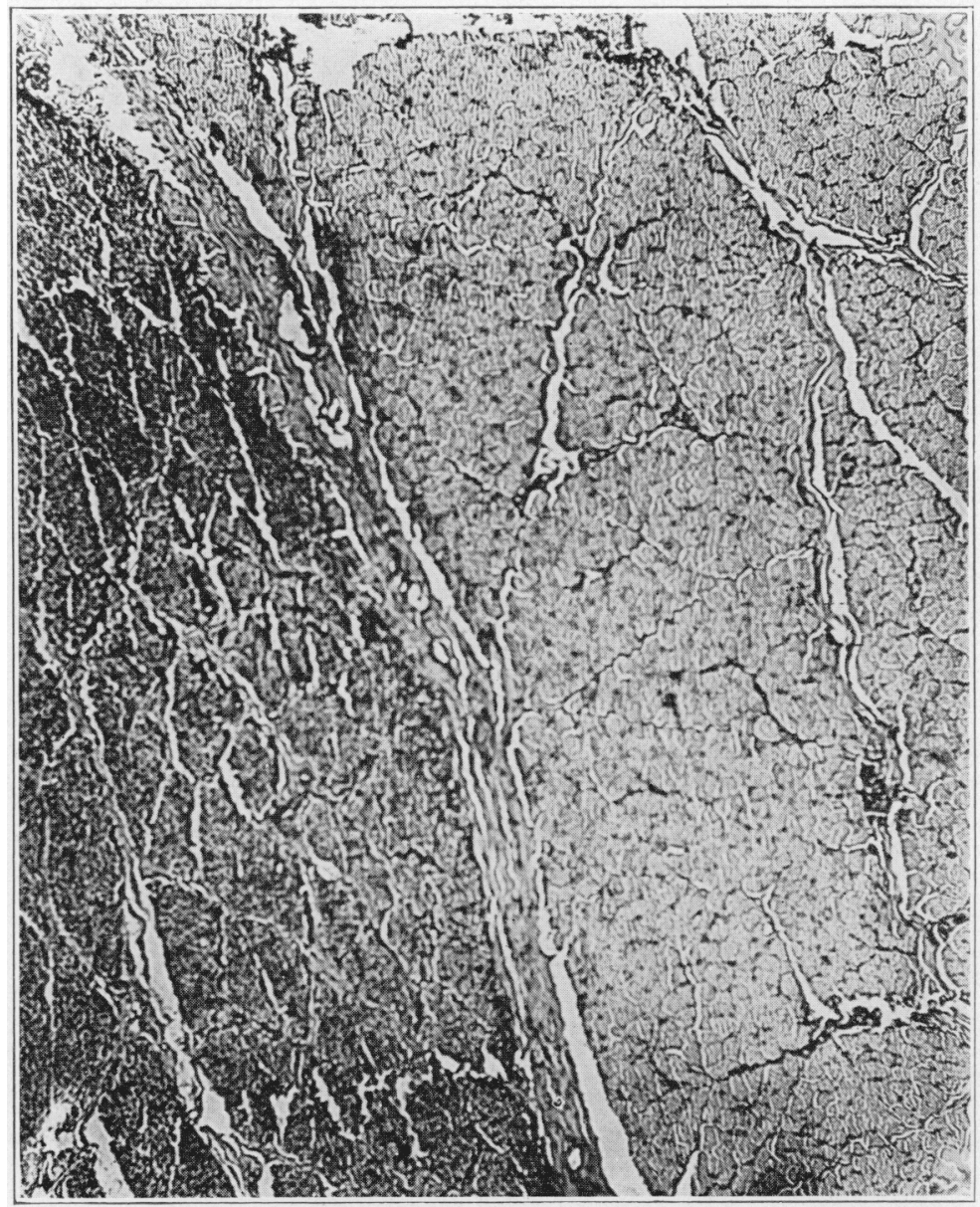

Fig. 1.-Photomicrograph of a cross section of the tibialis anticus muscle fourteen lays after ligation of the primary arteries of the extrenity, showing an area of degeneration of the muscle. The area of degeneration is sharply circumscribed. There is no evidence of acute inflammatory raction in the area of degeneration or in the surrounding nondegenerated muscle. See description of Experiment 37.

months after operation, the animal was apparently perfectly normal. It was killerl. The left femoral artery was divicled in the midthigh and the proximal stump injected with a thin paste made of ireshly precipitated barium sulphate. A roentgenogram of the entire aninal shower a complete injection of all the 
arteries of the hody. The paths of communication between the proximal and distal stumps of the ligated aorta was through the anastomoses of the mammary and the deep enigastric arteries. These antstomotic arteries lay in the rectus aldominis muscles. The communicating branches were surprisingly few in number and small in sioc. It was most remarkalule to lind that such a small arterial communication between the heart and the arteries of the pelvis conld

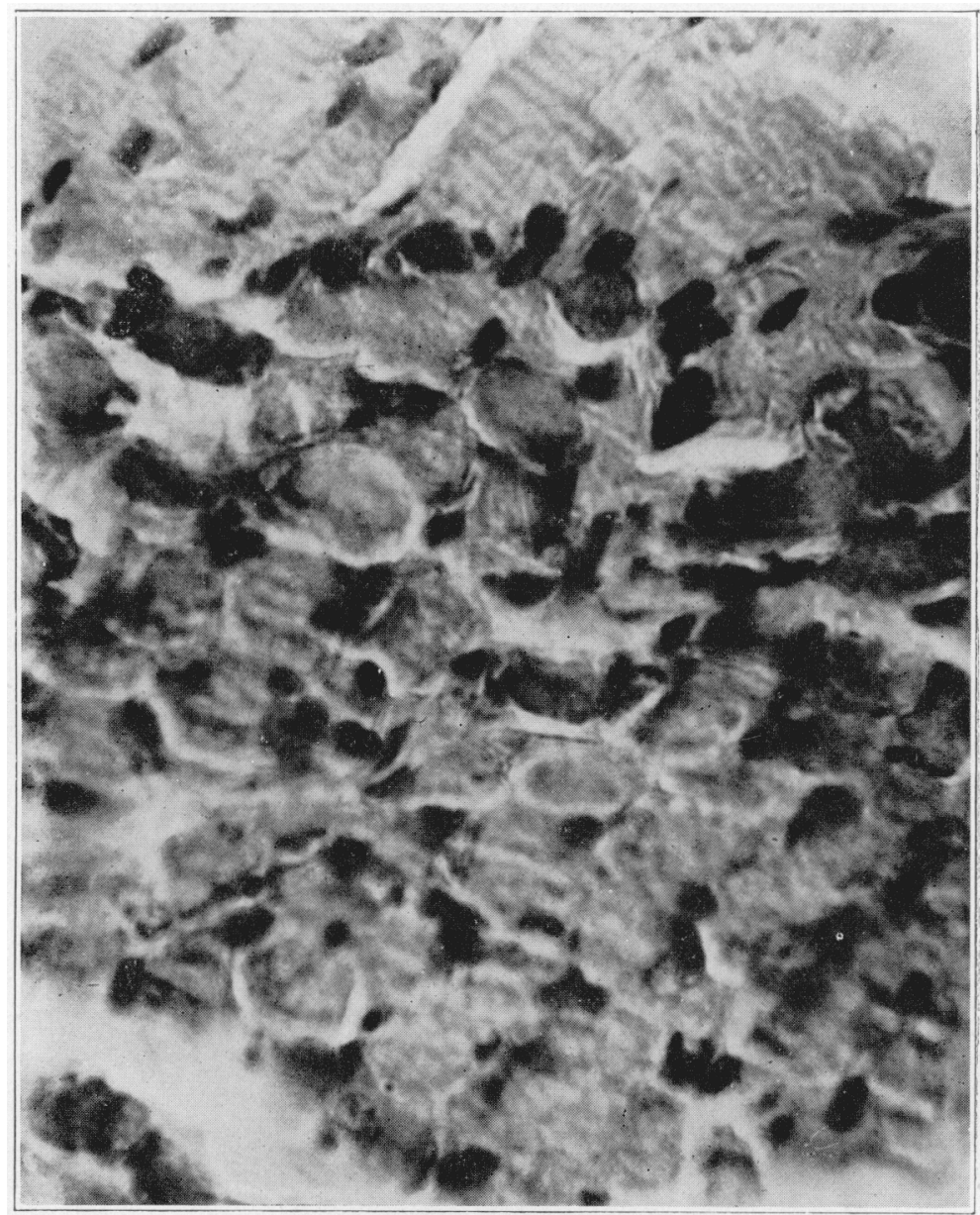

Fig. 2.-High power magnification of the degenerated area shown in ligune 1. The alsence of leutucytic infiltration or fibrons tisste formation may be noted.

weserve the anjarently perfect anatenic and functional integrity of the entire pusterior half of the leds:

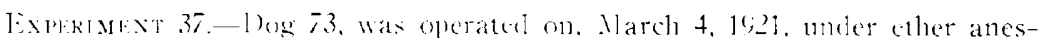
thesia. The abclomen was opened and the aurta ligated distal to the origin of the iliac arteries: the left iliac artery was ligated, and the ablomen was closed. An incision was mate in the middle of the left thigh and the fomumal artery was ligated. The wownd was closed. 
There bours after oneration the animal wathed on the lex. The lew felt cold: the muscles of the leg felt tense, and the animal walked ats if he hat a peg lew. There was no evilence of pain, no swelling, and no erkma. Six hours after eperation the condition was the same. The muscles of the leg were sense. No voluntary movement contal be detecterl. The animal thincherl irom a pin prick

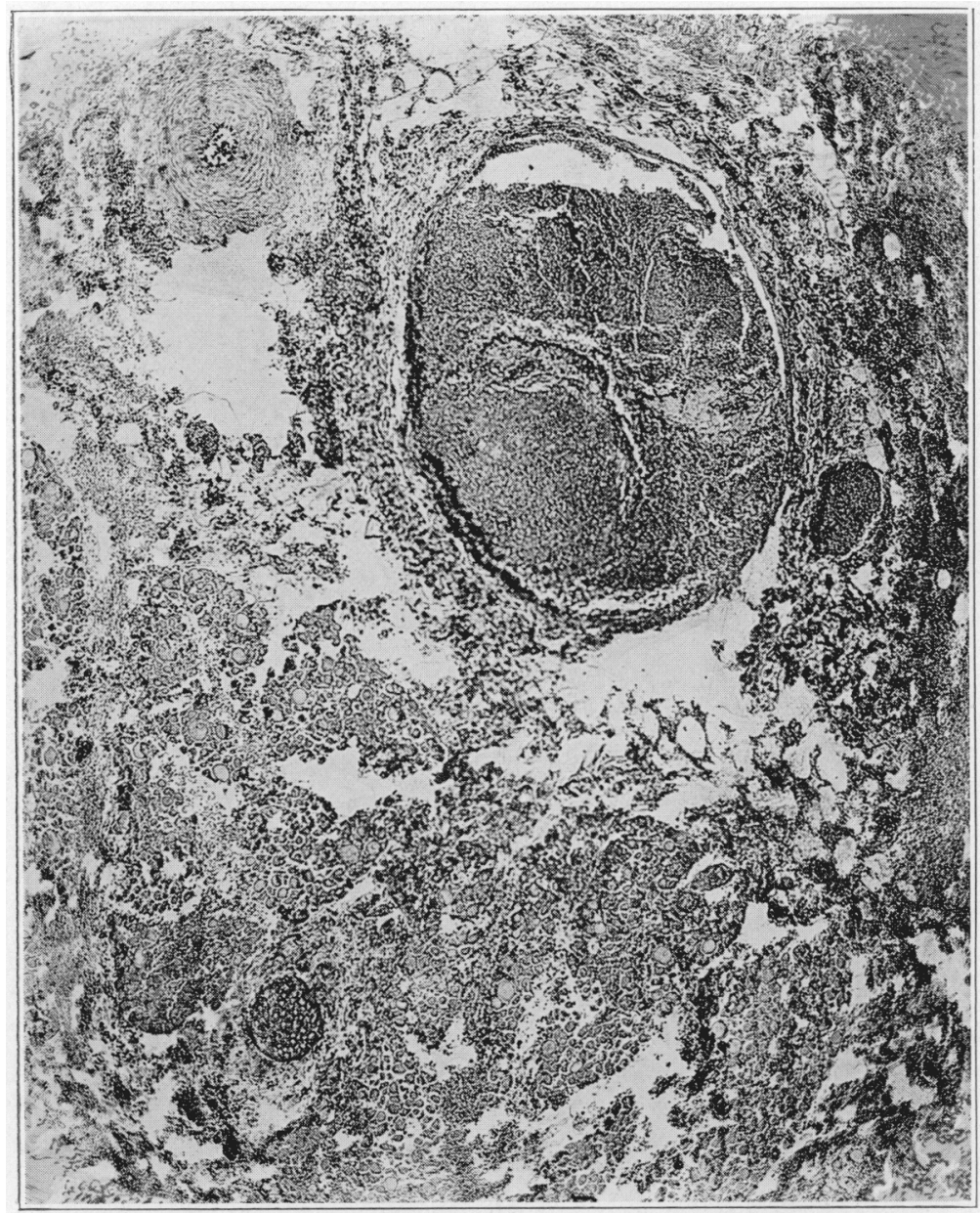

lïg. 3.-l'hotomicrograph of a cross sectim uf at "isolated muscle" twentyfour lours after ligation of its vein. showing extravasation of blood into tle muscle and nerses: the vein is accluded hy a thrombus: the artery is not thrombuserl.

anywhere in the leg. When the animal attempterl to step on the foot the tor turned backward. Twenty-fomr hours after operation the muscles of the les were tense. Apparently there was meakness but not complete paralysis. There was no swelling and no contracture. Two dass after operation the animal did not use the leg for walking. The muscles were held tense. There was no swelling below the knee. The thigh wat slighty swollen and apparenty the 


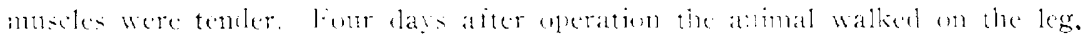
with a limp. The entere extremity was swollen. There wats an area we beginning wangrene of the shin on the medial strface of the lese and thigh. Fourteen days after operation, weil delined, try gangrene of the shin of the iont. leg, and Hewal thed of the thigh wat observed. The line of demaration of the gangrene was share. It encircled the thish at the junction of the mirlle and tistal

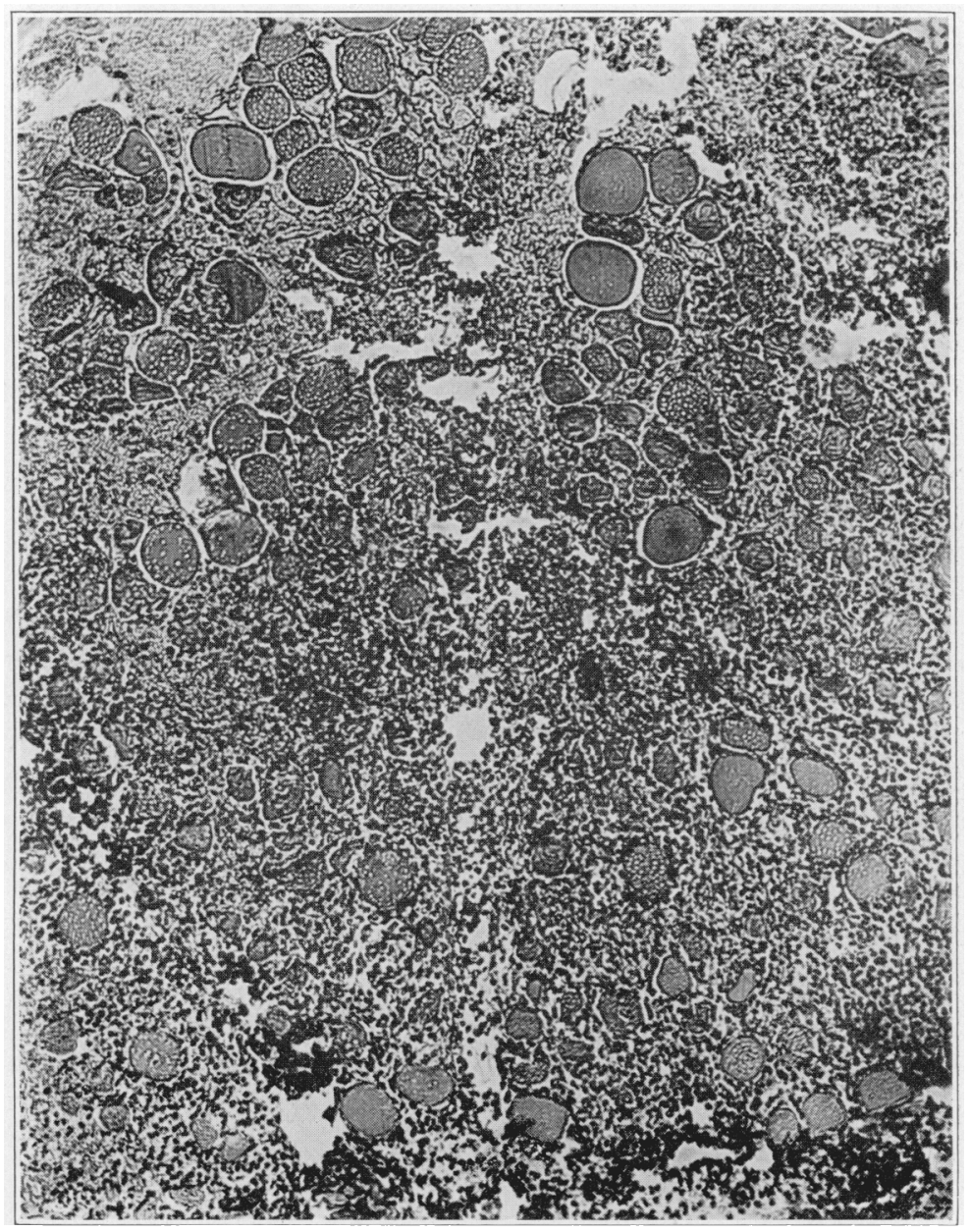

1.ig. 4.--Photomicrograph of a cross section of a muscle law lays after ligation of its vein, showing axtensive intiltration wi the muscle ly poly-

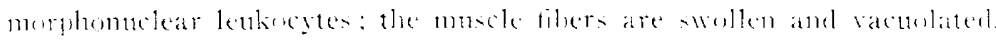

thirds. The animal was anestinctionel and the samprenons shin wats removed. The muscles of the thish and log apreared nermat. The tentons of the leg muscles were gangrenums in the fout. All the muscles contrated on stimulation of the muscles or nerves. On section all of the muscles angeared normal except the anterior tibial muscle. This musle anpeated mormal externally: but on 
section there was, in the substance of the muscle, a pale firm area, cylindric in shape, measuring $10.5 \mathrm{~cm}$. in diameter and extending the entire length of the muscle. This area harl the appearance of an infart.

Microscopic examination of the mucles showed no ahmormality exeept in the anterior tibial muscle. Micruscopic examination of this muscle in cruss

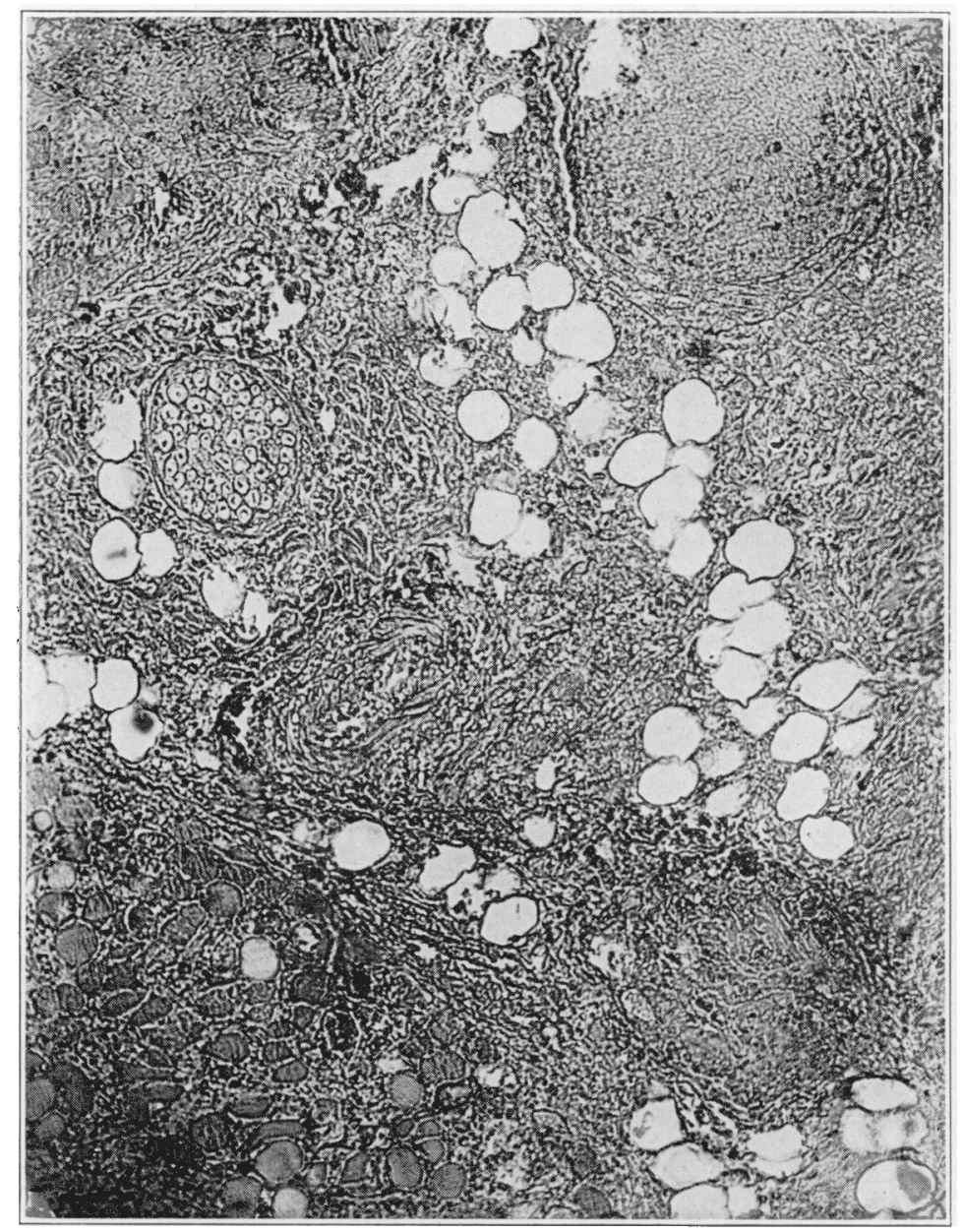

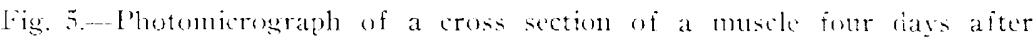
ligation of its vein, showing infiltation with polymorphonuclear lenkocytes and a beginning librous tissue reaction.

section showed the periphery of the muscle appoximately momal. The central pale area showed a marked change in the muscle tisste. The muscle tibers were much shrunken and clondy packed together. The nudei of the muscles stained well. Thete was no masive necrosis. There wats bers little reaction in the muscle stroma. The area of degencration wats sharply nelinted from normal appearing muscle. There was rery little reation at the periphery of the atea of 


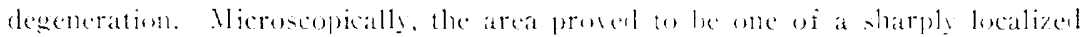
muscle desenteration rather than actual massive necrosis. Reaction within or about the areat of clegeneratinn was strihingly aldsent. A photomicrograph of this area and the surromoling muscle tissue is shown in ligure $i$.

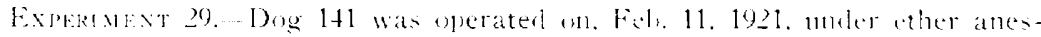
thesia. The aldomen was opened: all branches of the aurta distat to the origin

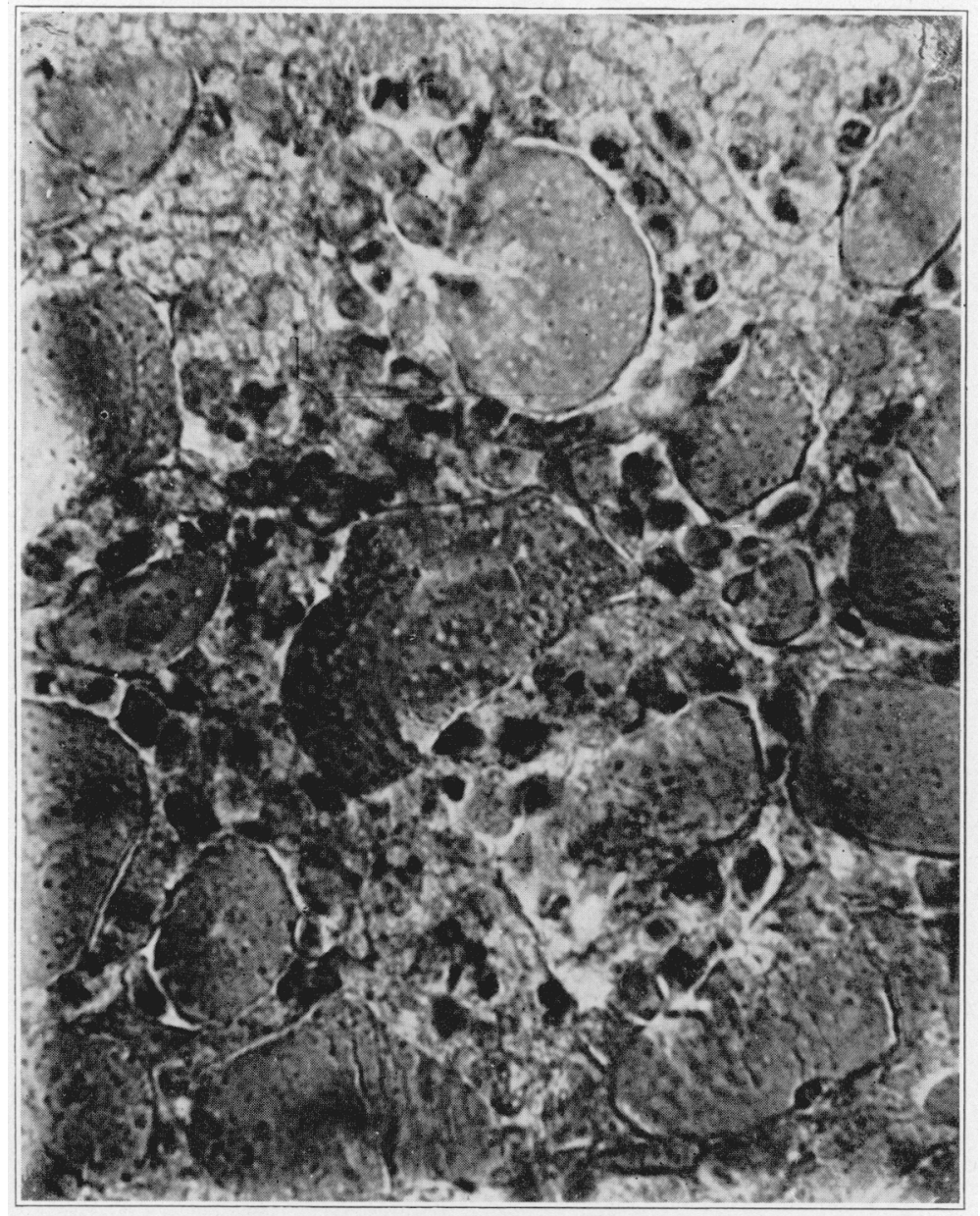

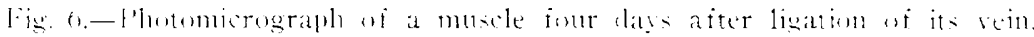

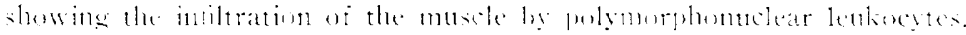

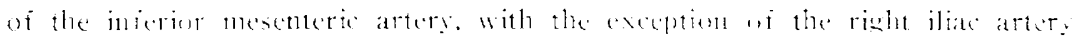
were ligated: the left deep ephestric was ligated near its origh from the ilia atters. and the aldemen was elesed. I small incioion was mate in the left milthigh at: the fenoral artery was ligated.

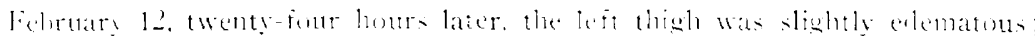

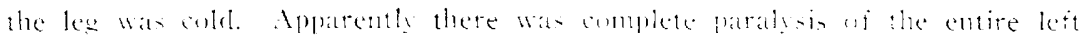


pusterior extremity. Through the skin. all muses folt normal. The muscles 1. f the ley contracted to strong faralic stimulation. Contractions were less powerful than in the right leg.

February 13, after forty-eight hours, the animal did not cat: it looked sick. The left thigh was tremendonsly swollen. There was no swelling below the linee. The entire extremity was apparently neless. There was rery slight

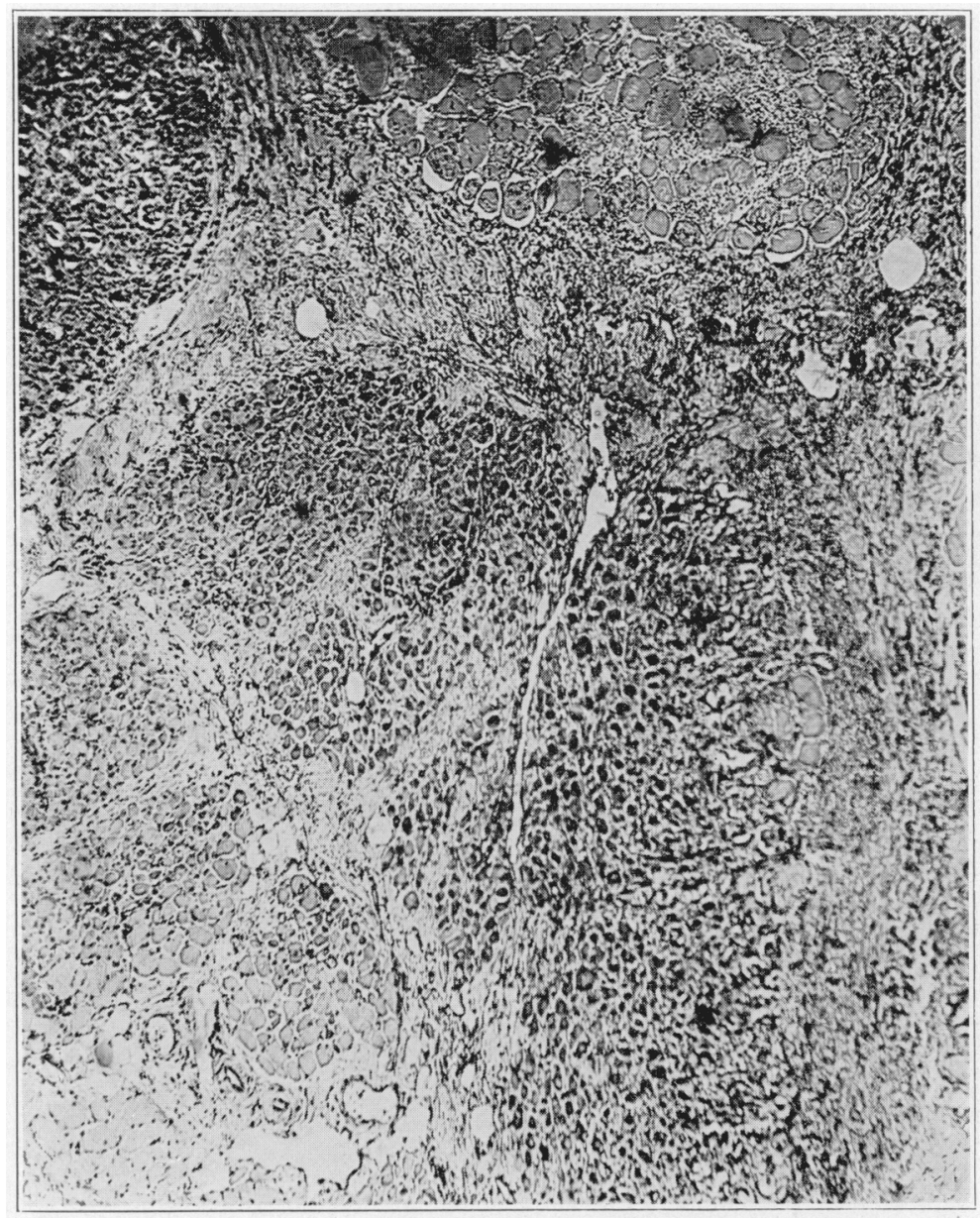

Fig. 7.-Photomicrograph of a cross section of a muscle ten days afier ligation of its vein, showing fihrous transformation of the muscle.

morement in the muscles at the hip and no motion ledow the knce. The skin of the thigh showed marked bluish discotoration. There was a iairly sharp line of clemarcation around the proximal thigh, between the discolored and normal skin.

The animal was anesthetized and the muscles of the extremity were examined hefore the animal was killed. Below the knee the muscles looked strikingly normal in color and form. They were not swollen. There wat no visible 
elema. The muscles dicl not react to electrical nor mochanical stimulation. Stimulation of the nerve trunks caused no contraction in the muscles below the knee. Stimulation of the sciatic nerve in the midthigh gave no effect on respiration.

The muscles of the thigh were trementously swollen and very pale. There was a large amotnt of fluid in the muscle and in the intermuscular spaces. The

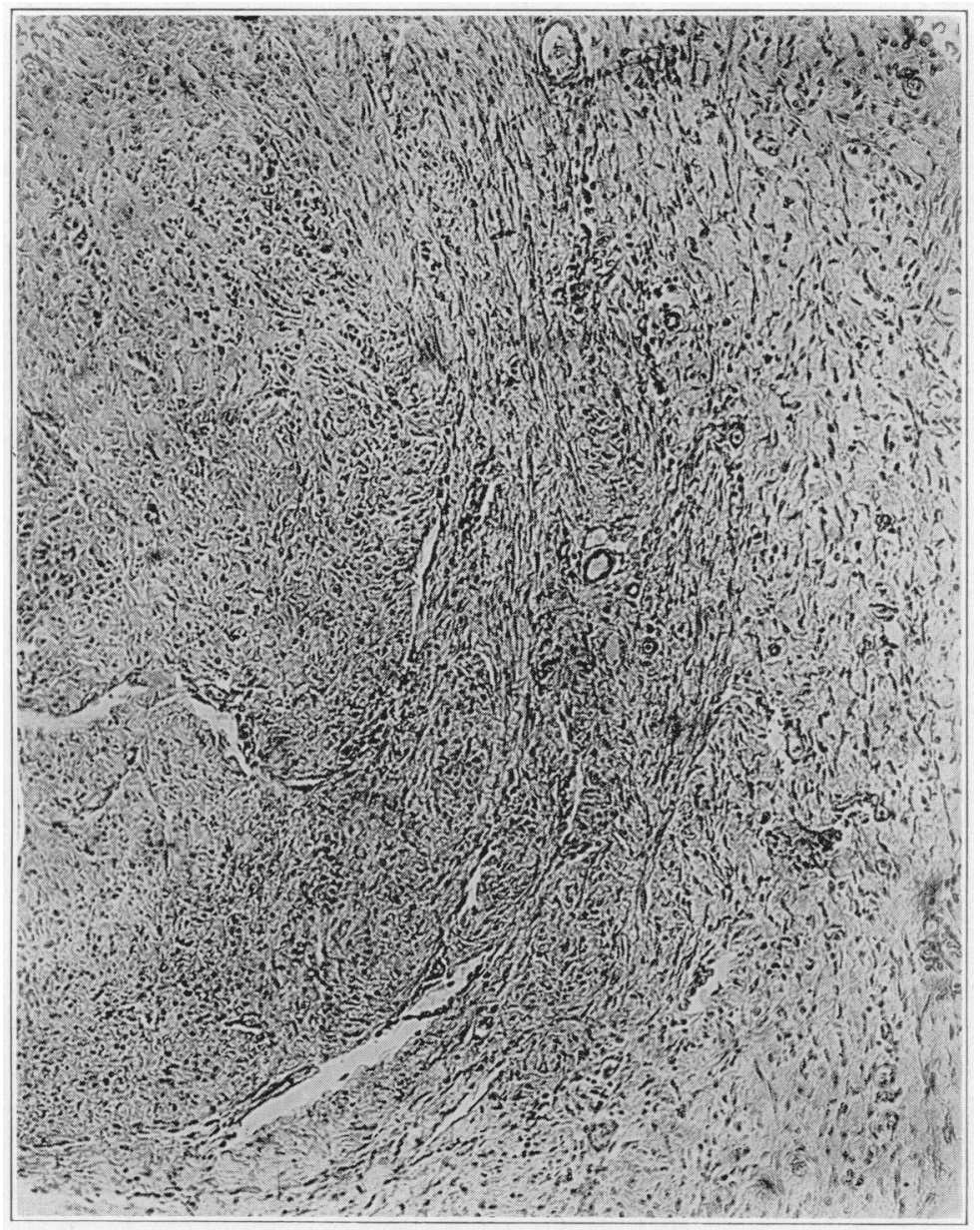

l.ig. 8.-Photomicrograph of a cross section of a muscle thirty-one tlays after ligation of its vein, showing complete fibrous transformation of the muscle.

muscles did not contract to mechanical or electrical stimulation. The muscles hecame red on exposure to the air.

The gluteus maxinutus muscle was brick red in color; it bled slightly on section. It contracted promptly on stimulation ly a strong faradic current. The contractions were weak and the muscle fatigued quickly.

All muscles were either totally paralyzed and necrotic or totally not paralyzed and viable, except the rectus femoris muscle. This muscle showed 
both conditions in the same muscle. The distal half was clearly necrotic and completely paralyzed, the proximal half was clearly viable and contracied promptly on electrical stimulation. The line of demarcation between the viable and nonviable muscle was sharply defined, and coincided with an equally sharp line of definition between the irritable and nonirritable muscle.

In Experiments 101, 37 and 29 just described, there were changes in physiologic and anatomic integrity of the muscles as a result of the obstruction of the arterial supply to the extremity.

In Experiment 101, in which the ligation of the aorta produced a marked diminution in the blood supply to the posterior extremities, there was a temporary change in the physiology of the muscles of the extremity but no demonstrable anatomic change. Immediately following the obstruction to the arterial supply the muscles of the extremities, although at no time completely paralyzed, were constantly in a state of exaggerated tension, and the extremity after even a few minutes of exercise became useless. This condition was relieved by rest and appeared again after repeated exercise. Three days after the arterial obstruction, the animal did not lose the use of the extremities after a considerably longer period of exercise; and at the end of four months, it showed nothing abnormal in function or structure of the muscles, although it was possible to establish only a very small arterial connection between the heart and the posterior extremities.

In other experiments it has been found that the loss of function of the posterior extremities after ligature of the aorta has been complete for two or three days and the period of complete recovery extended to several days; but in all instances in which the animal has not died or developed gangrene, the recovery has been complete and the muscles have shown no pathologic change.

The condition developed in this experiment corresponds to the condition, well known in clinical medicine, to which the term ischemia has been applied. It has been noted in man after occlusion of such large arteries as the common iliac or axillary. It is almost certainly a fatigue phenomenon. With the marked decrease in arterial blood supply, the muscle becomes rapidly profoundly fatigued.

In Experiment 29, in which the arterial blood supply to one extremity was markedly reduced by ligation of several arteries, gangrene of the extremity resulted. It is important to note that all tissues of the extremity were included in the necrosis. The muscles of the most distal portion of the extremity were apparently completely deprived of all fluid. They became necrotic en masse, without hemorrhage, edema, or any evidence of inflammatory reaction. Some of the muscles of the thigh were apparently deprived of blood but did absorb fluids from lymph vessels or neighboring viable tissues. Some of the muscles received enough circulation to preserve their normal physiologic reactions. It is 
interesting that the borderline muscles either became completely necrotic or remained wholly viable. The one exception to this was the rectus femoris muscle. The distal half of this muscle became gangrenous, and the proximal half remained almost normal in appearance. The junction of the dead and living muscle was sharply defined. Of even more interest, however, is the fact that the part of the muscle

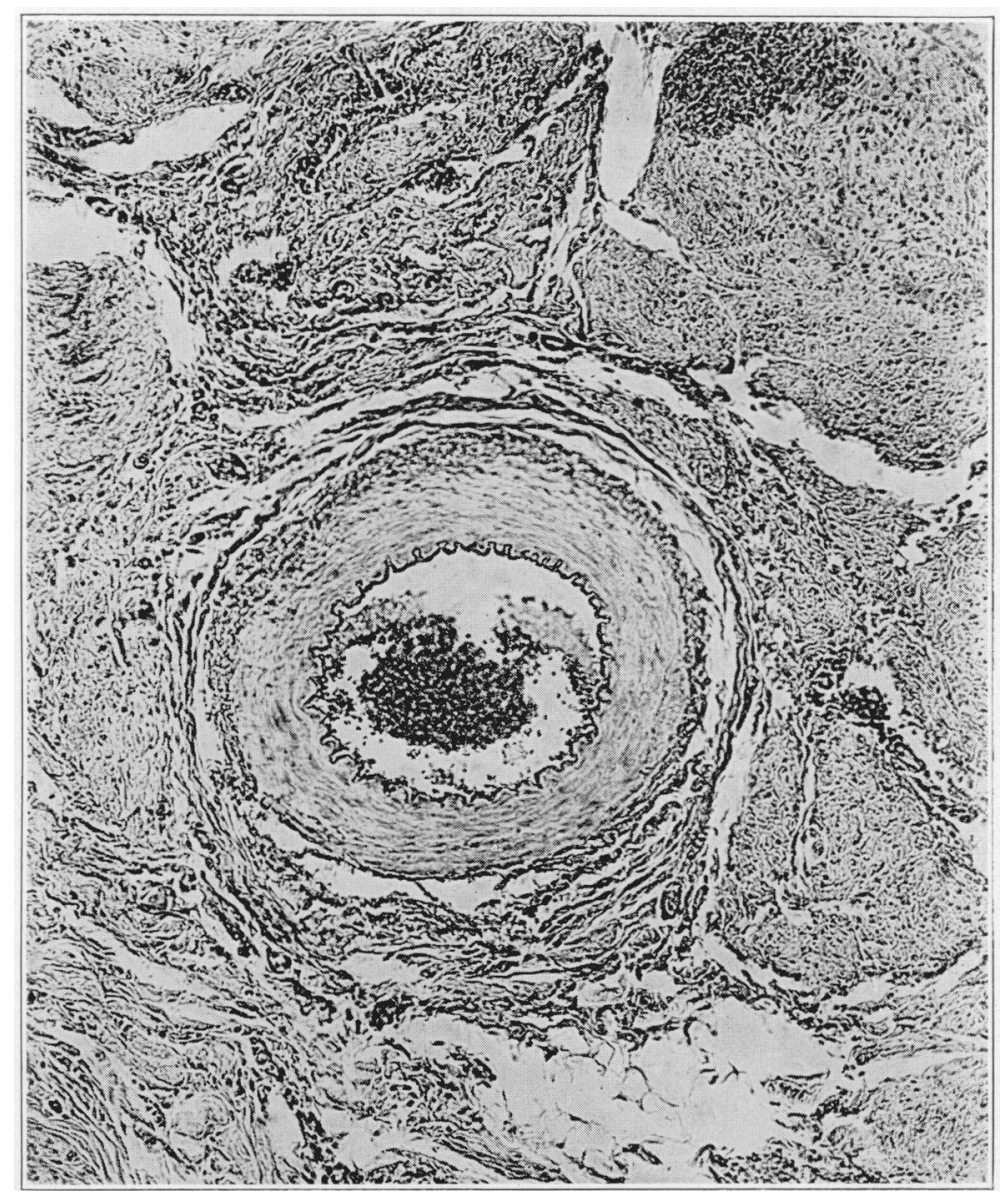

lig. 9.-Photomicrograph of another area of the section shown in Figure 8. showing the preservation of the arteries in the muscle.

which preserved its anatomic integrity also wholly preserved its physiologic properties (except, no doubt, this part of the mucle would have exhibited the phenomenon of rapidly dereloping fatigue or "ischemia"). In this long mucle. which gets its arterial supply near its proximal end. we are justified in assuming that following the obstruction to the large arteries the hood supply to this muscle 
Was most abundant at the proximal end and continuously decreased toward the distal end. Linder such conditions, therefore, there was no "zone" in which the blood supply was sufficient to keep the muscle alive but not sufficient to permit it to contract. It is, of course, theoretically possible that the blood supply of a muscle be just sufficient

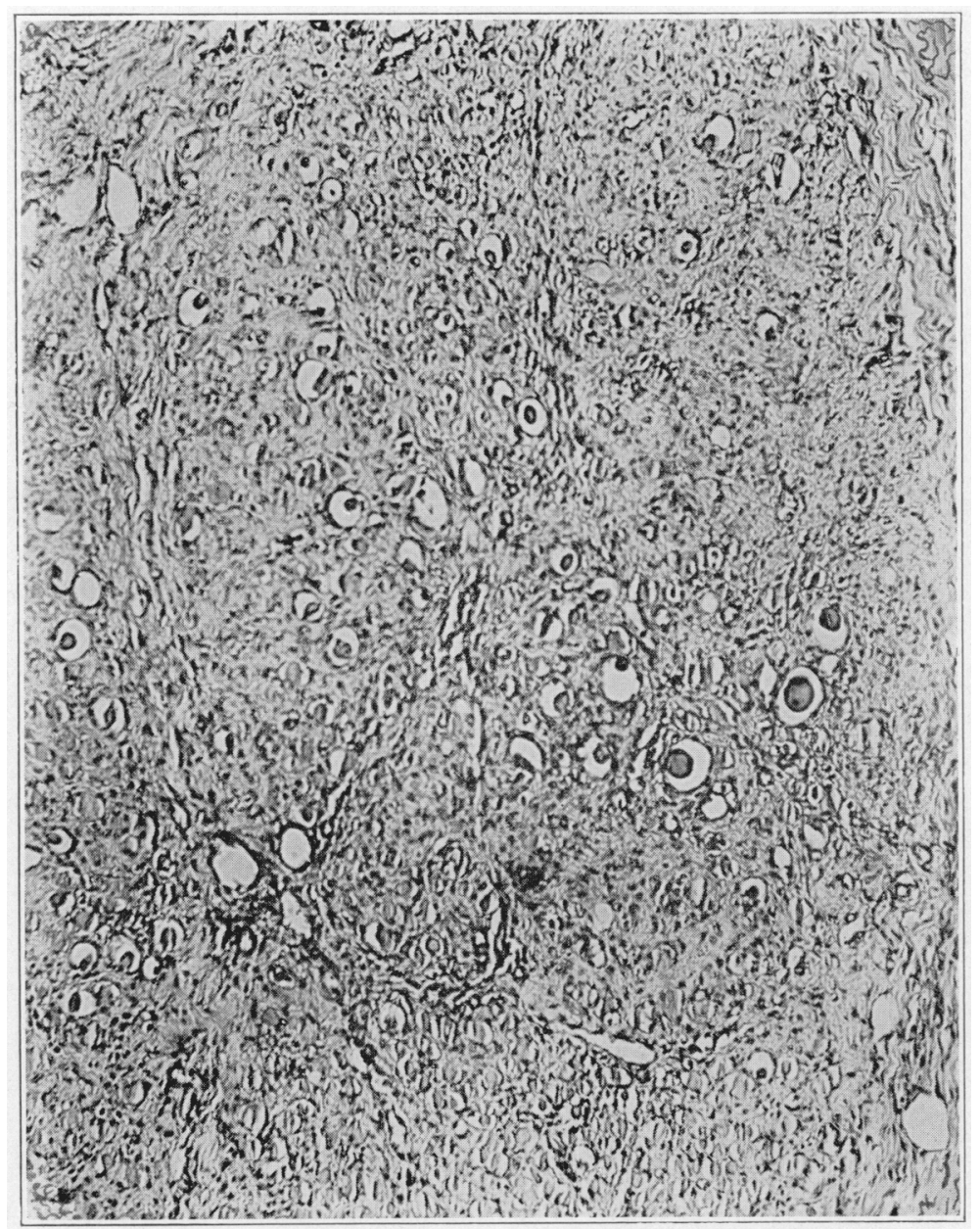

Fig. 10.--Photonicrograph of a cross section of a muscle thirty-six days after ligation of its vein, showing the fibrous transformation of the muscle. A few degencrating muscle fibers can be seen.

to take care of an infinitesimal amount of muscle activity so as to keep the muscle in a permanent state of complete fatigue. Practically, this is not possible because the blood supply of a region supplied by an artery is always most profoundly limited immediately after the 
obstruction of this artery. The quantity furnished by collateral circulation (if any at all is furnished) always increases for a certain period.

Experiment 37 is of particular interest because it was the only instance in which a process of degeneration rather than massive necrosis of muscle followed permanent occlusion of the arteries to an extremity. In this experiment there was an isolated area of degeneration of muscle fibers in a single muscle; the remainder of this muscle and all the other muscles of the extremity remained normal in appearance and reaction in spite of extensive gangrene of the skin.

In all of the experiments in which the arteries to an extremity were permanently occluded, and in which the diminution in blood supply to this extremity was sufficient to produce pathologic changes in the tissue. the skin showed the most extensive change.

\section{EXPERIMENTS IN WHICH THERE WAS A TEMPORARY OBSTRUCTION \\ OF THE PRIMARY ARTERIES OF THE EXTREMITY}

Experiment 33.-Dog 122, February 20, 10 a. m., under ether anesthesia, was operated on, the abdomen being opened and the aorta ligated distal to the origin of the iliac arteries. The deep epigastric artery was ligated. A clamp was applied to the left iliac artery. The abdomen was closed. An incision was made in the left thigh. The femoral artery was clamped and the incision closed.

February 20, 4 p. m., six hours after operation, the entire leg and distal half of the thigh were cold. The animal stood on the leg. It used the muscles of the thigh; but the muscles of the leg were held stiffly and apparently were useless. Electrical stimulation through the skin caused prompt contractions in the thigh muscles, very weak contractions in the posterior muscles of the leg, and no contractions could be obtained in the anterior leg muscles.

The animal was anesthetized and the clamps were removed from the iliac and femoral arteries. Pulsation immediately returned in the femoral arteries. The skin of the entire leg and of the distal half of the thigh became deeply flushed. There was a fairly sharp line of demarcation between the flushed skin and the paler skin in the midthigh. Ten minutes after removal of the clamps from the arteries all muscles of the leg reacted to electrical stimulation. The contractions in the anterior muscles were not so strong as normal. On the following day there was no visible paralysis. One week later the animal was killed and nothing abnormal could be found in the muscles of the extremity.

EXPeriment 34.-February 24, 4:00 p. m., on Dog 101, the same operative procedure was carried out as in Experiment 33.

February 25, 9:00 a. m., seventeen hours after operation, there was complete muscular paralysis below the knee, but no swelling. The leg was not cold. Electrical stimulation of the muscles below the knee caused no contractions.

February 25, 4:00 p. m., twenty-four hours after operation, there was complete paralysis below the knee. The leg felt cold. The animal was anesthetized and the clamps were removed from the iliac and femoral arteries. Pulsation immediately returned in the femoral artery. The skin below the knee was flushed to a bright pink. The flush was sharply defined at the level of the knee. Five minutes after removal of the clamps there was no demonstrable electrical irritability of the muscles below the knee. 
February 26, complete paralysis existed below the knee. The muscles of the leg were swollen and definitely harder than normal.

February 28, four days after clamping the vessels and three days after removal of the clamps, the muscle paralysis remained unchanged. The entire extremity was swollen. It was definitely warmer than the normal leg. The swelling was apparently entirely in the deeper structures. The skin looked normal; the femoral pulse was good. There was no contraction of the muscles below the knee from electrical stimulation. Pain sense was apparently impaired below the knee but it was not absent. The animal was anesthetized. An incision was made exposing the deeper structures of the leg and thigh. All the larger arteries of the extremity pulsated. There was good pulsation in the arteries of the foot.

The muscles of the leg were swollen, harder than normal, and of a blue hemorrhagic color. On section of the muscle there was active bleeding from the larger arteries in the muscle. There was, however, no capillary bleeding and no demonstrable irritability of any muscle of the leg.

The muscles of the thigh were particularly interesting. The gluteus maximus muscle appeared normal and was irritable. The same was true of the rectus femoris and sartorius muscles. The deeper extensor was swollen, hemorrhagic, and showed no irritability. The distal half of the lateral extensor muscle of the thigh was swollen, hemorrhagic and completely paralyzed; the proximal end appeared normal and contracted normally on electrical stimulation. The junction of the abnormal muscle and normal muscle was sharply defined and coincided absolutely with the junction of the irritable and the paralyzed muscle.

Microscopic examination of the muscles of the leg showed the muscle fibers strikingly normal in outline. In some areas there was a complete absence of staining of nuclei, giving a picture of massive necrosis of all the tissues. In other areas there was hemorrhage between the fibers and an accumulation of a few polymorphonuclear leukocytes. The larger arteries contained blood and showed no evidence of thrombosis. Many arteries and veins, however, were thrombosed. In general the areas of hemorrhage and leukocytic infiltration were near the arteries which were not thrombosed. The paralyzed muscles of the thigh showed much the same picture, except that the areas of hemorrhage and leukocytic infiltration were relatively more extensive, and the areas in which there was massive necrosis without evidence of any reaction were smaller.

A longitudinal section of the junction of the paralyzed and nonparalyzed portions of the lateral extensor of the thigh showed varying grades of muscle necrosis and degeneration limited to a small zone. The more distal portion of the muscle was completely necrotic, with no hemorrhage or leukocytic infiltration. Proximal to this was a zone of hemorrhage and leukocytic infiltration. Normal appearing fibers reached to this zone, but in the immediate proximity of the hemorrhage some of the muscle fibers were very much swollen and fragmented.

Experimfixt 36.-Dog 61, on March 2, under ether anesthesia, was operated on, the abdomen being opened and the clamps being applied to (1) the aorta distal to the origin of the iliac arteries, (2) the left iliac artery, and (3) the left femoral artery in the midthigh.

Seventeen hours after operation there was apparently compiete paralysis below the knee. The knee was extended and the foot was flexed. The leg was held stiffly; the muscles were tense. The foot and leg were cool but not 
cold. Stimulation of the muscles of the leg caused no visible contractions. The animal was anesthetized and all clamps were removed. A feeble pulse returned in the femoral artery. The skin below the level of the knee was flushed pink. There was no demonstrable evidence of return of irritability of the muscles of the leg.

March 4, the animal walked on the leg with a limp. "Paralysis" was not complete.

March 9, six days after removal of the clamps from the arteries, there was no contracture of the muscles. The animal did not use the leg for walking; but apparently it was not completely paralyzed. There was a small ulcerating area in the skin. The animal was anesthetized. The skin was dissected away and the muscles were inspected before the death of the animal. The anterior muscles of the leg were very pale and showed no contraction after electrical or mechanical stimulation of the nerves. The posterior muscles of the leg were mottled with areas of pink muscle and pale yellowish muscle. The pink areas contracted on electrical stimulation. The pale areas showed no sign of being irritable. A similar picture was shown by the muscles of the thigh.

The results of these experiments in which there was temporary obstruction of the arteries to an extremity are different from those in which the obstruction was permanent. In the latter the demonstrable pathologic change was always most extensive in the skin, while in the former the most extensive damage was in the muscles. In Experiment 33 in which the arteries were obstructed for six hours, the leg. became cold, completely paralyzed, and some of the muscles showed no irritability to electrical stimulation. Following the removal of the obstruction to the arteries, there was an immediate return of function of the muscles and no demonstrable anatomic change in any tissues of the extremity.

In Experiment 34 in which the arteries were obstructed for seventeen hours, and in which the relief of this obstruction was followed by a good pulse in all of the larger arteries of the extremity, there was at the end of four days extensive necrosis of the muscles. This necrosis was accompanied by the presence of a large amount of hemorrhage and edema. The skin was not at this time visibly changed. The muscle necrosis was so extensive that it included all, or most, of the muscles of the extremity. The muscles in general became completely necrotic or remained completely viable; half of one muscle of the thigh was necrotic and the other half was viable and retained its physiologic reactions. This extensive necrosis occurred in spite of a restoration of a pulsating blood stream in all of the larger arteries, even the arterial branches to the muscles bled within the necrotic muscles. The reaction of the tissues of the extremity to the extensive damage following the obstruction to the circulation was interesting. During the period of arterial obstruction there were no manifestations of inflammation. One day after the removal of the obstruction to the arteries there was some 
swelling, and at the end of four days the swelling had increased and the extremity was distinctly warmer than the normal extremity. At this time microscopic examination of the muscles showed some infiltration of leukocytes in the vicinity of functioning blood vessels. There was, however, no evidence of a fibrous tissue reaction at this time.

Experiment 36 is interesting from the standpoint that arteries of the extremity were obstructed for the same period as in Experiment 34; but following the removal of the clamps, the circulation was not completely restored to the large arteries. The femoral artery had only a very feeble pulsation. The extent of muscle damage was distinctly less than in Experiment 34, and there was at the end of six days no evidence of hemorrhage and edema of the muscles. Also there was not at any time any swelling or manifestations of marked inflammatory disease. There was, however, ulceration of the skin. This experiment is interesting in its relation to the belief of Rowland that ischemic contractures were the result of the sudden release of obstruction to arteries after a period of anemia, and to the generally accepted treatment of the anemia of the extremity following exposure to cold, in which it has been found that a gradual restoration of circulation or more accurately a gradual restoration of the normal temperature is not so likely to produce disastrous results as the sudden warming of the extremity.

\section{EXPERIMENTS ON THE ISOLATED MUSCLE}

In order to study more accurately the effect of circulatory disturbance on the muscles, independent of the other tissues of the extremity, a series of experiments on the isolated muscle were carried out. The rectus femoris muscle was chosen on account of its accessibility and the fact that its circulation is supplied by a single artery and vein which are easily isolated. Also the nerve supply is a single branch of the femoral nerve which accompanies the nutrient artery and vein. The experimental method which was the same in all experiments is described below.

The dog was anesthetized and an incision was made on the anterior surface of the thigh and distal third of the abdomen. The rectus femoris muscle was freed from the surrounding tissues everywhere except from tendinous origin from the ilium and insertion into the quadriceps tendon. The artery, nerve, and vein were completely isolated from one another and the fibrous tissue accompanying them was divided. A tight ligature was tied about each end of the muscle. This gave a muscle completely isolated from all vascular connections except a single artery and a single vein. The nerve supply was intact. The circulation in the surrounding tissues was normal. The following series of experiments were carried out on these isolated muscles. 
1. Section of Nerve: Artery and Vein Intact.-In the experiments in which the nerve alone was sectioned, leaving the isolated muscle with its artery and vein intact, the muscle was completely paralyzed. It decreased markedly in size and microscopic examination showed marked diminution in the size of the muscle fibers and loss of definition in striation. Occasionally fibers which showed degeneration were found. There was no evidence at the end of periods of as long as a month of any inflammatory reaction or fibrosis. The process was one primarily of atrophy rather than degeneration.

2. Injection of Blood into the Muscle.-In two experiments after isolation of the muscle, 10 c.c. of blood was aspirated from the femoral vein and injected into the body of the muscle in several places, so that the muscle was markedly distended with blood. In another experiment the same procedure was carried out and in addition the artery was tied. The animals in which these experiments were carried out were killed at the end of one month. Examination of the muscles showed nothing abnormal in their physiologic reactions; and microscopic examination showed no evidence of inflammation or fibrosis.

3. Ligature of the Artery Leaving Vein Intact.-In eleven experiments only the artery of the isolated muscle was ligated. In these experiments, therefore, a single muscle was completely separated from all arterial supply. The nerve and vein remained intact. The circulation of the surrounding tissues was not disturbed. The operation wounds were carefully closed so as to obliterate all cavities. The animals were killed at the end of periods of from seven to sixty days and the muscles were examined. In every instance the muscle showed normal physiologic properties. The muscles were always more adherent to the surrounding tissues than normal. In no instance was the muscle fibrous. Microscopic examination of the muscles showed slight degenerative changes in some instances; but in no instance was there found marked inflammatory reaction or fibrous change of the muscle.

In one experiment the artery and nerve were sectioned. Examination of this muscle after a period of sixty days showed the typical atrophy of nerve paralysis.

In five experiments the artery of the isolated muscle was tied and in addition the circulation of the entire extremity was diminished by ligation of branches of the aorta. In one of these experiments the iliac artery was tied after the isolation and ligature of the nutrient artery to the rectus muscle. Examination of the muscle three days later showed the muscle edematous; but the physiologic reaction was normal and microscopic examination showed only slight degeneration and inflammatory reaction. The infiltration with leukocytes was only what would be expected as a result of the operative trauma. In another experiment in which the conditions were the same, the muscle 
was normal at the end of seven days. In the three other experiments, the circulation in the extremity in which the muscle was isolated from all its arterial supply was further diminished by ligation of the iliac and hypogastric arteries. In each instance the isolated muscle was found completely absent, from seven to twelve days after operation.

In seventeen experiments, therefore, in which the arterial blood supply of an isolated muscle was obstructed, the muscle either retained wholly its normal physiologic and anatomic characteristics or it became completely necrotic and wholly disappeared. In no instance did the anemia result in an acute inflammatory process. In those experiments in which the muscle remained viable, it must have received its nutrition from the surrounding tissue or by a reversed circulation in its vein until the time of establishment of a new circulation by vessels growing in from the surrounding tissues. In some of those instances in which the large arteries of the extremity were ligated in addition to obstruction of the individual arterial supply of the muscle, the available supply of nutrition was so diminished that the isolated muscle did not survive the period of complete absence of arterial blood. Whether this was due to the diminution of the blood supply to the surrounding tissues, to the lowering of the pressure in the vein, or to a combination of both factors, is not clear. The importance, however, of the preservation of unobstructed veins to an extremity with a diminished blood supply has been demonstrated in some experimental work not included in this paper. It has been found that with an existing venous obstruction in an extremity gangrene is more likely to follow ligation of the large arteries of the extremity.

The importance of preservation of the patency of the vein is also suggested by the results obtained in the following experiments.

4. Ligation of Both Artery and Vein.-In four experiments with the isolated muscle, both artery and vein were ligated, thus cutting the muscle free from all vascular connections. In two of these experiments the muscle showed no pathologic change at the end of periods of forty and one hundred and ten days. In two other similar experiments the muscle was found necrotic in one case in two days and in the other completely absent in twenty-one days.

5. Experiments in Which the Iein Alone Was Ligated.-In nineteen experiments the isolated muscle was prepared and the vein alone was ligated leaving the artery and the nerve intact. These muscles were examined at the end of periods varying from one to one hundred and twenty days. In every instance marked pathologic changes were found.

Within an hour after operation the muscle becomes swollen, hard, and a dark blue. Stimulation of the muscle or nerve to the muscle 
at this period usually gives a very slight contraction. At the end of twenty-four hours there is a tremendous extravasation of blood into the muscle and an accumulation of bloody fluid around the muscle. The muscle will bleed if cut. At forty-eight hours there is a marked accumulation of polymorphonuclear leukocytes about the muscle fibers. At this time many of the muscle fibers are clearly necrotic. In four days there is a marked connective tissue proliferation and extensive degeneration of muscle fibers. At ten days there is formed between the muscle fibers a large amount of connective tissue. There was usually muscle tissue in some amount at all periods at which muscles were examined ; and whenever muscle fibers were present, some contraction could be demonstrated in the muscle. The progress of the fibrosis was in two instances so complete that no muscle tissue could be demonstrated in the isolated muscle. The marked inflammatory reaction and subsequent fibrosis always extended beyond the muscle and involved the surrounding tissues so that the muscle became embedded in a fibrous tissue mass. Contracture of the muscles was always present and in some instances the contracture of the single muscle was of such an amount as to prevent the normal flexion of the knee joint.

The details of the stages of the pathologic changes in the isolated muscle which followed occlusion of the vein are shown in the photomicrographs.

In these experiments in which a muscle was cut off from all circulation except that of a single artery and vein, and the vein was completely occluded leaving the artery intact, a constant pathologic change in the muscle resulted. This change was characterized by an initial period of acute inflammatory changes in the muscle and subsequently the development in the muscle of an extensive fibrosis. The fibrosis in some instances replaced a large portion of the muscle fibers and decreased very markedly the power of the muscle. In other instances the substitution of the muscle fibers by fibrous tissue was complete. The constancy of the pathologic process and the certainty with which it follows the experimental method described are important points.

\section{SUMM ARY}

The results of these experiments are evidence for the statement of certain general conclusions as to the probable effect of the obstruction of the circulation of blood on the function of an extremity, particularly as it concerns the muscles.

The results of permanent obstruction of the principal artery or arteries to an extremity may be stated as follows:

1. There may be no demonstrable change in the anatomy or physiology of the extremity. This result, of course, only follows if 
the circulation through the collateral anastomotic branches is sufficient. It is surprising indeed to find how small a collateral anastomotic arterial bed may prove sufficient.

2. A condition of ischemia in which there is no demonstrable anatomic change in the muscles may follow obstruction of the artery. After a period of voluntary muscle contractions, the extremity may become useless, in which state it remains only for a limited time. With rest the muscles again resume their function. This condition is probably a phenomenon of fatigue. In the dog the condition of ischemia always becomes less marked from day to day and ultimately disappears completely as far as could be observed in animals which were permitted the freedom of an "animal yard." It is possible that if some of the animals which had apparently recovered completely had been subjected to longcontinued walking symptoms of ischemia would have become manifest. A state of chronic ischemia existing for years has been observed by Halsted in a man whose common iliac artery was ligated, and I have under observation a woman in whom one common iliac artery was ligated nine months ago who complains of weakness and cramps in her leg after walking "four blocks." It is worth while calling attention to the differences in ischemia after ligation of a large artery and that accompanying general arterial disease, the former always improves, while the latter may progress.

3. The permanent obstruction of the arterial supply of an extremity may result in gangrene. If gangrene develops it is more extensive in the skin than in the muscles. If the muscles are involved there is a tendency for the individual muscles to become totally necrotic or remain wholly viable. If a part of a muscle becomes gangrenous and part remains viable, the line of demarcation is sharp and coincides with the line of separation between the physiologically dead and physiologically living muscle. It is seemingly impossible to reduce the arterial supply to a muscle to a point where it is physiologically dead but anatomically alive. This is theoretically possible but practically impossible for the reasons that the limits of arterial blood supply which would be compatible with such a state must be proximate, and the blood supply to an extremity, particularly after ligation of its artery or arteries, must be continually changing. The results of temporary deprivation of the arterial blood supply to an extremity by temporary occlusion of arteries are less definite but more interesting.

It would seem from these experiments that although muscles stand better than skin a continued diminished blood supply, they stand less well a temporary absence of arterial blood. This is an important point which I do not believe has as yet been pointed out. Another fact which is to be emphasized is that after obstruction of an artery for a period of several hours and the subsequent removal of this 
obstruction the pulse may return in the artery and all of its major branches and yet the circulation may not be reestablished in large areas of tissue.

The temporary occlusion of the primary arteries of an extremity may, therefore, result in no demonstrable anatomic or physiologic change after the removal of the obstruction if the obstruction has existed only a few hours. If the obstruction exists longer there may be scattered foci of necrosis or degeneration of muscle or extensive massive necrosis of muscles and skin if the period of anemia is prolonged for as much as seventeen hours. This necrosis may take place in spite of a resumption of pulsation in all of the larger arteries of the extremity. The pathologic change in the muscles is associated with extensive edema and hemorrhage, but with a very slowly developing inflammatory reaction; and there is not a rapidly developing fibrosis and contracture of the muscles.

The experiments on the isolated muscle are in accord with the experiments in which the primary arteries of the extremity were ligated as regards the effect of diminishing the arterial supply to a muscle, that is, the muscle either becomes wholly necrotic and disappears completely or remains wholly viable and shows no pathologic changes. The results of the obstruction of the vein of the isolated muscle with the preservation of the artery are different from any results obtained by artery occlusion. Under these conditions there was found a constant pathologic change, the outstanding features of which were hemorrhage, edema, degeneration of muscle fibers, and an acute inflammatory process which progressed to the more or less complete fibrosis of the muscle. This fibrosis is associated with contracture and loss of power of the muscle. The process may convert the muscle into a veritable fibrous mass which is incorporated in a similar fibrosis of the surrounding tissues. Simple hemorrhage in the muscle with or without interference with the arterial or nerve supply of the muscle does not cause a similar result.

The explanation of this pathologic process is one concerning which it is interesting to speculate. The slowing of the circulation is the first phenomenon observed in the process of inflammation. In blocking the veins the circulation is thus primarily slowed down and all of the succeeding manifestation of inflammation and repair follows. On the other hand a slowing of the circulation must follow an obstruction of an artery but inflammation does not result. It might be supposed that the venous obstruction asphyxiated the tissues and caused an accumulation of toxic waste products which damaged the muscle cells to the point of necrosis and the inflammation and repair processes follow the presence of this dead tissue. Were this true, a similar process should just as rapidly develop after temporary obstruction of the artery. Such is not the case. It, therefore, seems more likely that the initial 
stimulus of the process is more mechanical than chemical. With the occluded vein and the open artery the pressure in the capillary system must rise above diastolic blood pressure. This pressure probably results in a more or less complete destruction of the entire capillary system. The destruction of the capillary system would certainly interfere with the nutrition of the tissues, and degeneration or necrosis of tissues might result. It would seem, however, that the acute inflammatory reaction and subsequent fibrous tissue formation were the result of the mechanical injury to the vascular system rather than the presence of degenerate or necrotic tissue. The magnitucle of the reaction is certainly much greater than that seen about areas of necrosis.

The clinical application of these conclusions deserves some comment. A muscular weakness associated with a certain stiffness which follows the occlusion of a large artery may be a phenomenon of ischemia. Under such conditions one would not expect a complete paralysis and there would be no immediate manifestations of inflammation or contracture. This muscular weakness would be very likely to improve with the development of a more adequate collateral circulation. It would always be exaggerated by exertion and improve with rest. It is not associated with a fibrous transformation of the muscles. A complete muscular paralysis of any portion of the extremity which follows the occlusion of an artery is evidence of an anemia of the tissues incompatible with viability and usually signifies impending gangrene. With the development of gangrene the skin will almost certainly become necrotic to a higher level than the muscles. The permanent occlusion of a large artery is not followed by acute inflammatory disease. Anemia and inflammation are incompatible pathologic processes. Any condition, therefore, which develops within twenty-four or forty-eight hours, and which is characterized by heat, swelling, pain, and a subsequent fibrosis cannot be the result of permanent occlusion of an artery.

The phenomenon of edema of the tissues as a result of obstruction to an artery is interesting. Edema may follow obstruction of an artery. It is not constant either in amount, site of appearance, or time of appearance. In general, we believe edema follows the reestablishment of circulation in vessels to tissue which has already been damaged. Edema, therefore, follows the development of collateral circulation or the release of the original arterial block permitting blood to flow into tissue which previously had become in whole or in part degenerate. Edema does not make its appearance in tissues wholly deprived of blood nor in tissues in which the blood supply has remained adequate. It does appear in tissues between these extremes and is, therefore, found in the tisstues near the line of demarcation in instances in which gangrene occurs, as a result of permanent occlusion of an artery, or in tissues 
which have been deprived of blood completely for a limited period by the temporary occlusion of an artery. Keeping in mind this principle, therefore, it would seem that the time of appearance and the site of development of edema would be indicative of the development or nondevelopment of gangrene. For example, if the primary arteries of the posterior extremity were permanently occluded and edema of the thigh, and not of the leg, marle its appearance in twenty-four hours, one could feel almost certain that the leg was to become gangrenous. On the other hand, if the edema made itself apparent in the foot at the end of twelve hours the chances of gangrene would be much less. In case of temporary occlusion of an artery the amount of edema would depend on the amount of tissue which had been damaged, and the extent of return of the circulation to the tissues in proximity to degenerate tissues.

The pathologic process following the marked obstruction to venous return of blood from tissues in which the arterial supply is not obstructed is of the nature of an inflammatory rather than a degenerative process. Degeneration or actual necrosis are present; but it is selective in nature and does not include all of the tissues of the muscle. The muscle fibers may in part degenerate or become entirely necrotic; but the interstitial connective tissue is stimulated to active proliferation and the processes of inflammation and repair completely overshadow the degenerative changes. Furthermore, the proliferation of the connective tissue elements when thus set going seems to continue for a period of several weeks, and the end-result is the transformation of the muscle into a mass of fibrous tissue. This process is one which sets in almost immediately after the venous occlusion and progresses with rapidity in the muscle leading to an early loss of function and contracture.

The pathologic changes following temporary occlusion of the primary arteries of an extremity have some of the characteristics of both those following permanent occlusion of the artery and those following occlusion of the vein. If the artery is occluded for a certain period the tissues of the extremity become degenerate in part. In other words, some tissues can remain viable without circulation for longer periods than others, or certain areas have their normal circulation or nutritive mechanism destroyed before other areas. If then the obstruction to the primary artery is removed and the blood flows back into the extremity, those tissues which have remained viable and retained their normal circulation or nutritive mechanism resume more or less their normal condition, while those tissues which have become necrotic, or had their normal circulation destroyed, become as foreign bodies in the living tissue. The living tissues react under such condition; and inflammation, absorption, and fibrosis follow. In the experiments which I have observed, however, in no case has the connective tissue reaction 
been so marked as in those instances in which acute venous obstruction was produced. The degenerate areas have appeared to run the usual course of slow replacement by fibrous tissue as is seen in the usual anemic infarct.

That the classic picture of Volkmann's ischemic paralysis could only be explained on the basis of acute venous obstruction would seem quite clear. As a matter of fact, however, it is customary to refer to every case of contracture following the application of a tight bandage, tourniquet, plaster cast, or splint as Volkmann's ischemic contracture. Undoubtedly, some of these cases are due to pure local pressure necrosis, entirely analogous to the decubitus ulcer, or pressure sore on the heel or over the anterior superior iliac spine from continued pressure of a plaster cast. I have seen recently a patient in whom a fracture of the forearm which was treated by splints left in position for two weeks showed, after ten years, a marked contracture of the wrist in hyperextension and the thumb in a position of complete flexion and adduction across the palm. There was an extensive scar over the dorsal surface of the distal prominence of the radius and another deep scar where the end of the anterior splint rested in the palm. The patient gave a history of deep ulcerations being present when the splints were removed. In this patient there was marked atrophy of the extensor muscles of the forearm; but exploratory operation showed the tendons of these muscles incorporated in the deep scar on the dorsum of the wrist. The bellies of the muscles were soft and showed the normal nerve muscle reaction and no evidence of fibrosis. In such a case the continued pressure of a board splint against a bony prominence for two weeks with a local deep pressure necrosis is an entirely satisfactory explanation of the contracture.

In those instances in which a bandage or splint is applied to an extremity presumably never so tight as to obstruct immediately and completely the circulation distal to constriction, and in which there follows in the course of a few hours great pain and cyanosis which make the constriction no longer bearable, and in which removal of the splint is followed by swelling, heat, tenderness, and a rapidly developing contracture, one is forced to the assumption that the etiologic factor is either an acute venous obstruction or a temporary pressure anemia followed by a reestablishment of circulation through the damaged tissue. The ease with which the former is reproduced experimentally is evidence of its being the most important etiologic factor of contractures following the application of constricting dressings in the treatment of fractures. The reproduction of areas of degeneration and subsequent fibrosis of muscles by temporary anemia is so difficult experimentally that it is rather unlikely that the exact set of conditions for its causation would be present in any clinical instance. 